
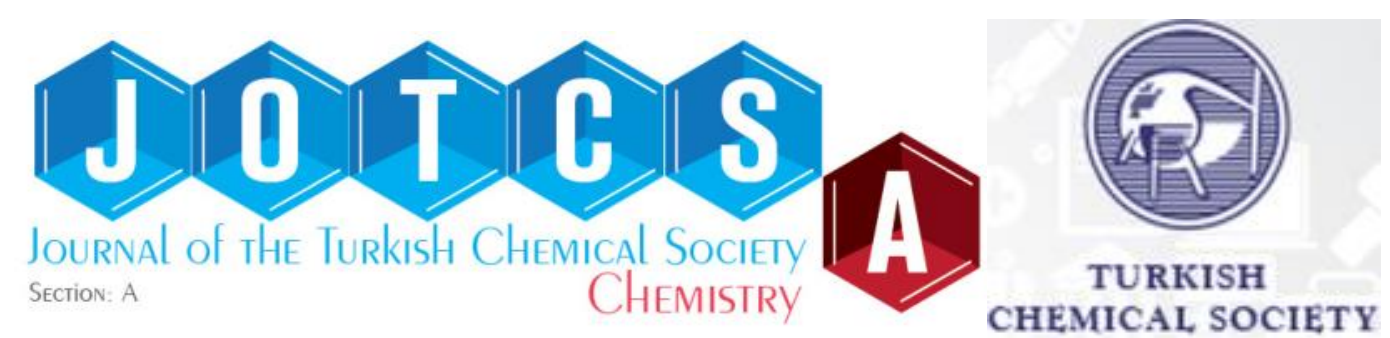

\title{
PREPARATION OF POLY(PYROMELLITIC DIANHYDRIDE-CO- THIONIN) MODIFIED VOLTAMMETRIC SENSOR FOR THE DETERMINATION OF EPICATECHIN
}

\author{
Serap TİTRETIR DURAN* \\ *Department of Chemistry, Faculty of Arts and Sciences, İnönü University, 44280, Malatya-Turkey.
}

Abstract: In this study, the electrochemical oxidation of epicatechin and its voltammetric sensing is shown at a sensitive platinum electrode modified with poly(pyromellitic dianhydride-co-thionin). The electrochemical response of the sensor was improved in the presence of both electro-inactive (sucrose, fructose, lactose) and electroactive (gallic acid, cafeic acid, ascorbic acid) interferants and displayed an excellent analytical performance for the determination of epicatechin. A linear response was obtained over a range of epicatechin concentrations from $0.05 \mathrm{mM}$ to $0.30 \mathrm{mM}$ and was shown to be useful for quantifying low levels of epicatechin in phosphate buffer solution, PBS, pH 7.00. Regression coefficient (R2) was found to be to be 0.9969 . Limit of detection (LOD) was calculated as $1.8 \times 10^{-5} \mathrm{M}$ by using $3 \mathrm{~s} / \mathrm{m}$. Where $\mathrm{m}$ is the slope of the calibration curve and $\mathrm{s}$ is the standard deviation of the calibration graph calculated using the Excel Steyx function.

Keywords: Modified electrode, Polyimide, Sensors, Epicatechin, Voltammetry.

Submitted: July 23, 2018. Accepted: September 03, 2018.

Cite this: Titretir Duran S. PREPARATION OF POLY(PYROMELLITIC DIANHYDRIDE-CO-THIONIN) MODIFIED VOLTAMMETRIC SENSOR FOR THE DETERMINATION OF EPICATECHIN. JOTCSA. 2018;5(3):1021-8.

DOI: http://dx.doi.org/10.18596/jotcsa.446953.

*Corresponding author. E-mail: serap.titretir@inonu.edu.tr.

\section{INTRODUCTION}

Electrochemical sensors, providing a crucial analytical tool for rapid, sensitive and selective determination of various kinds of analytes, have been widely applied in many fields, such as detection of water quality, clinical chemistry and food quality control. Researchers are mainly working on the design and preparation of various polymeric materials to modify electrodes and the modified electrodes then be used for better electrochemical sensing (1). Polymer modified electrodes have received a great attention in recent years (2). Electrochemical detection of an analyte is a very elegant method in analytical chemistry. An interest in developing electrochemical sensing devices to be used in environmental monitoring, clinical assays or process control is growing rapidly.

Catechins are compounds regarded as important for human health. Epicatechin (EC) is a polyphenol with strong antioxidant properties found in vegetable sources, especially in green tea, cocoa, and grapes. Epicatechin and its derivatives have been shown to possess antibacterial, antiviral, antiallergic, anti-inflammatory, anti-aging and anti-tumor properties, as well as inhibiting tumor growth, preventing wrinkling, eliminating heavy metal toxicity, reducing bacterial inflammation, improving immunity and exhibiting anti-rotavirus activity $(3,4)$. Additionally, epicatechin pretreatment has been reported to prevent mice exposed to gamma rays from causing more damage to the 
liver (5) and testis (6). In other a study the radio protective property of such phytochemicals has been evaluated, epicatechin, belonging to the group of flavanols, is one of the most potent antioxidants present in the human diet predominantly in grapes, tea, apples and cocoa (7). Studies conducted by some researchers indicate that epicatechin may have a great influence on factors related to cancer metastasis (8).

It is very important to develop a simple, sensitive, accurate and sensitive method for the determination of epicatechins from food, medicine and cosmetic products. For this purpose, many methods such as nuclear magnetic resonance spectroscopy (NMR) (9), high performance liquid chromatography (HPLC) (10-13) thin layer chromatography (TLC) (14-17). Spectrophotometry $(18,19)$, GC-MS (20) and electrophoresis (4, 21) are used. However, these methods have some disadvantages such as the difficult sample preparation and measuring steps, time consuming and costly. However, in the determination of epicatechin, electrochemical methods have important advantages such as rapid response time, low detection limit, low cost, high reproducibility (22) and film thickness controllability (23). In recent years, polymer coating on electrodes namely electrode modification methods has shown considerable potential for application in the field of sensors (24). The electrochemical detection of epicatechin through adsorptive stripping voltammetry on poly $(3,4-$ ethylenedioxythiophene)-modified Pt electrodes was investigated (25). The mechanism of electrochemical oxidation of epicatechin (EC) on a glassy carbon electrode was investigated over a wide range of conditions, using cyclic and square-wave voltammetry (26).

The aim of the present study was to develop an electrochemical method that will have important advantages such as rapid response time, low detection limit, low cost and high reproducibility for the determination of epicatechin. For this aim, polyimide membrane based voltammetric sensors were developed for epicatechin determination. As the polyimide membrane, poly(pyromellitic dianhydride-co-thionin) (PI), which has a very high film forming property was used to remove the interferants from the electrode surface in the analysis medium. In recent years, polyimide-based materials have attracted great interest, both in industry and in academia, because they exhibit unique properties not shared by conventional polymers (27). Polyimides have important advantages such as physical properties, adhesive, thermal stability and mechanic strength $(28,29)$. For this reason, polyimides are widely used in the field of sensors as permselective membranes $(27,28)$.

\section{EXPERIMENTAL}

\section{Reagents and Apparatus}

Reagents were of analytical grade or of the highest commercially available purity. The polymer, poly(pyromellitic dianhydride-cothionin), used for the modification was purchased from Sigma-Aldrich. Epicatechin solutions in $0.1 \mathrm{M}$ phosphate buffer solution (PBS) at $\mathrm{pH}=7.00$ were prepared just before running each experiment. Gallic acid, cumaric acid, ascorbic acid, and epicatechin from Sigma-Aldrich were used. Ultra-pure water was obtained from the Millipore brand Elix 20 model water system.

BAS (Bioanalytical System Inc.) 100BW electrochemical analyzer with C2 cell stand was used for voltammetric measurements. $\mathrm{pH}$ measurements were performed by using a $\mathrm{HI}$ 2211 model pH/ORP Meter. pH meter was frequently calibrated using standard $\mathrm{pH}$ buffers obtained from Merck. A KERN model $A B J-N M / A B S-N$ electronic balance was used for weighing. In a classical three electrode cell configuration working electrode was Platinum electrode (MF 2014). A platinum wire electrode (BASI MW-1032) was used as auxiliary together with an $\mathrm{Ag} / \mathrm{AgCl}(3 \mathrm{M} \mathrm{KCl})$ reference electrode (CHI111). Platinum electrode was mechanically cleaned using 15 , 3 and $1 \mu \mathrm{m}$ aqueous diamond pastes successively on diamond polishing pads and $0.05 \mu \mathrm{m}$ alumina slurry on alumina polishing pads. After each polishing operation electrodes were rinsed with distilled water and ultrasonicated 2-3 minutes in an ultrasonic bath (Branson model 3510).

All glassware including electrolysis cells were kept in $6 \mathrm{M} \mathrm{HNO}_{3}$ overnight to remove impurities.

\section{RESULT AND DISCUSSION}

\section{Preparation of poly(pyromellitic dianhydride-co-thionin) Electrodes}

Before starting chemical modification of electrodes, the surface of working electrode was carefully cleaned and polished as described above. Firstly, about $0.1 \mathrm{~g}$ of poly(pyromellitic dianhydride-co-thionin) is dissolved in $1 \mathrm{~mL}$ of $\mathrm{n}$-methylpyrrolidone (NMP). Then, different volumes $(1,2,3,4$ and $5 \mu \mathrm{L}$ ) of the poly (pyromellitic dianhydride-cothionin) solution were dropped on the surface of bare platinum working electrodes. Afterwards poly(pyromellitic dianhydride-co- 
thionin) film was dried at room temperature for at least $72 \mathrm{~h}$.

The oxidation steps of EC were located on benzene ring containing two hydroxyl groups<smiles>Oc1cc(O)c2c(c1)O[C@H](c1ccc(O)c(O)c1)[C@H](O)C2</smiles><smiles>C=[Co+]</smiles>

on 3' and 4'-position, which represents a typical redox system with two electron oxidation process as showed in Figure 1.

(-)-Epicatechin (EC)

Figure 1. Oxidation mechanism of EC.

Effect of Polyimide (PI) Film Thickness

The most effective parameter that determines the permselectivity character of polymeric films is the thickness. At first, platinum electrodes were coated with by dropping different volumes $(1,2,3,4$, and $5 \mu \mathrm{L})$ of poly(pyromellitic dianhydride-co-thionin) onto Pt electrode surfaces. Afterwards, DPV responses of the electrodes towards ascorbic acid (AA), gallic acid (GA), caffeic acid (CA) and epicatechin (EC) injections were separately measured for each film thickness in 0.1 M PBS solution $(\mathrm{pH}=7.0)$. Injected volumes of each analyte were carefully calculated so that final concentrations of the analytes were $2 \mathrm{mM}$. All of the solutions, regardless of what kind of analyte it contained and what the polymer film thickness was, also contained a mixture of lactose, sucrose and fructose, each at a concentration of $2 \mathrm{mM}$. Figure 2 shows the effect of PI film thickness
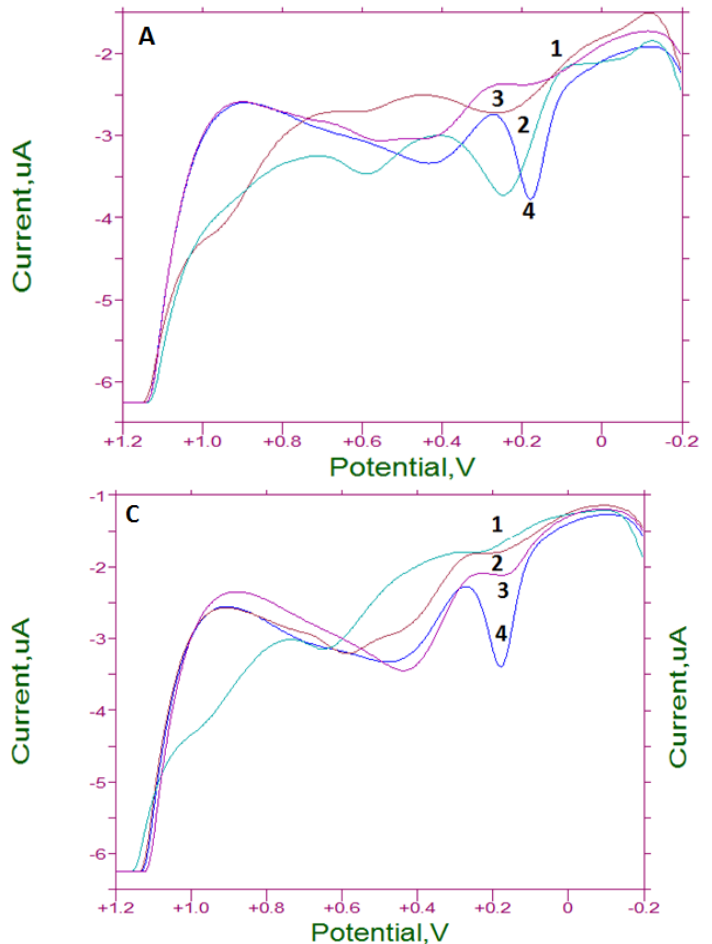

upon DPV peak magnitudes of epicatechin and the electroactive interferants ( $A A, G A$ and $C A$ ) on electrodes coated at 5 different thicknesses. It is seen that at relatively thin film coatings electroactive interferants produced responses, although much smaller than that of EC, almost at the same potential as with EC. However, their responses at that potential diminished slowly with the increasing film thickness. At a film thickness of $4 \mu \mathrm{L}$ PI it was evident that electroactive species did not interfere with the EC signal. It must be stated here that the same species are known to exhibit electroactivity with a bare Pt electrode. Furthermore, no interference effect was detected from nonelectroactive species of lactose, sucrose and fructose. As a result, optimal coating for electrochemical detection of epicatechin was that performed with $4 \mu \mathrm{L}$ of PI.
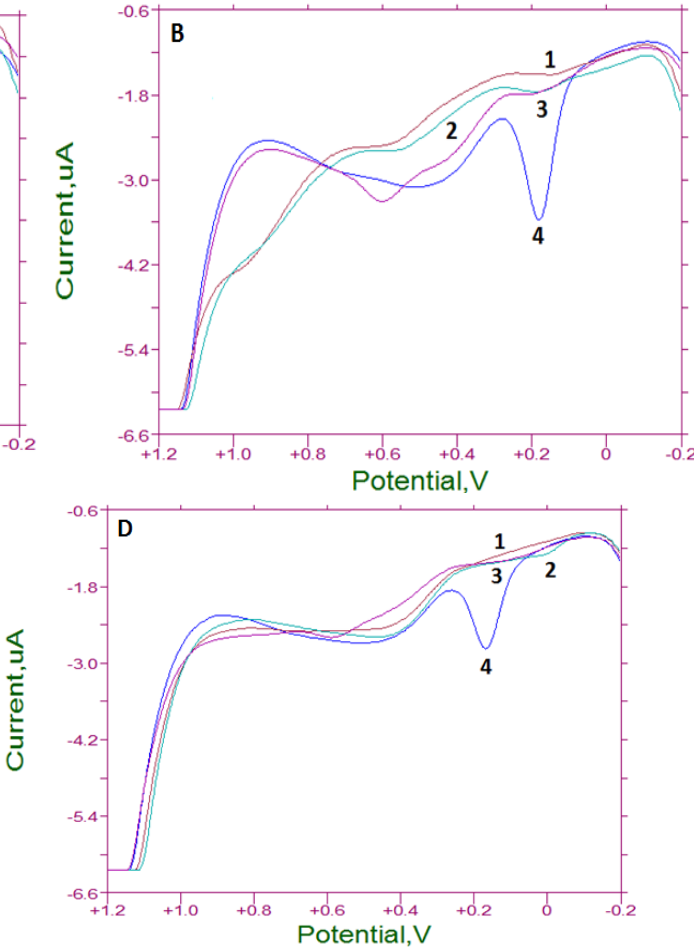


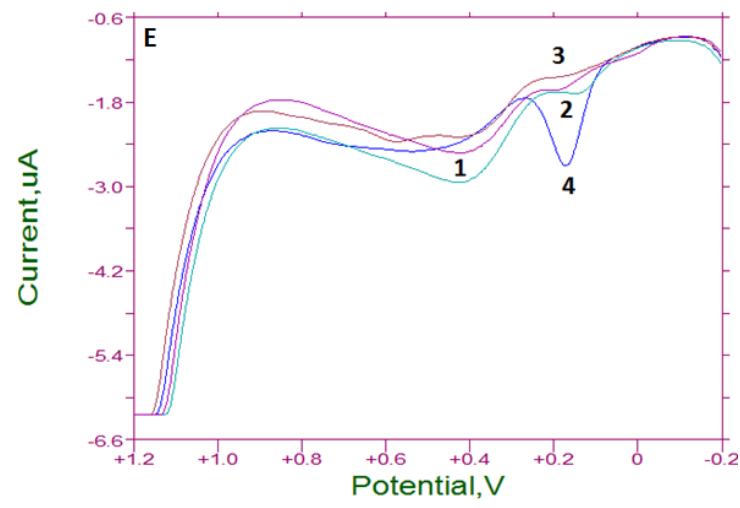

Figure 2. Effect of the $\mathbf{A}: 1, \mathbf{B}: 2, \mathbf{C}: 3, \mathbf{D}: 4, \mathbf{E}: 5 \mu \mathrm{L}$ PI film thickness on the DPV of $2 \mathrm{mM}$ 1: $A A, \mathbf{2}$ : $\mathrm{GA}$, 3: $\mathrm{CA}, 4$ : $\mathrm{EC}$ in $\mathrm{PBS} \mathrm{pH}=7.00$ containing $2 \mathrm{mM}$ lactose, sucrose and fructose.

\section{Effect of Scan Rate}

To see the effect of scanning rate on epicatechin signal, DPVs of $2 \mathrm{mM}$ epicatechin at different scan rates were taken on PI electrode of optimal thickness in PBS pH 7.00.
The peak currents of epicatechins obtained under these conditions are shown in Table 1. As shown in Figure 3 that optimum scan rate is $20 \mathrm{mV} / \mathrm{s}$. It is clear that the peak currents are smaller at higher and lower scan rates.

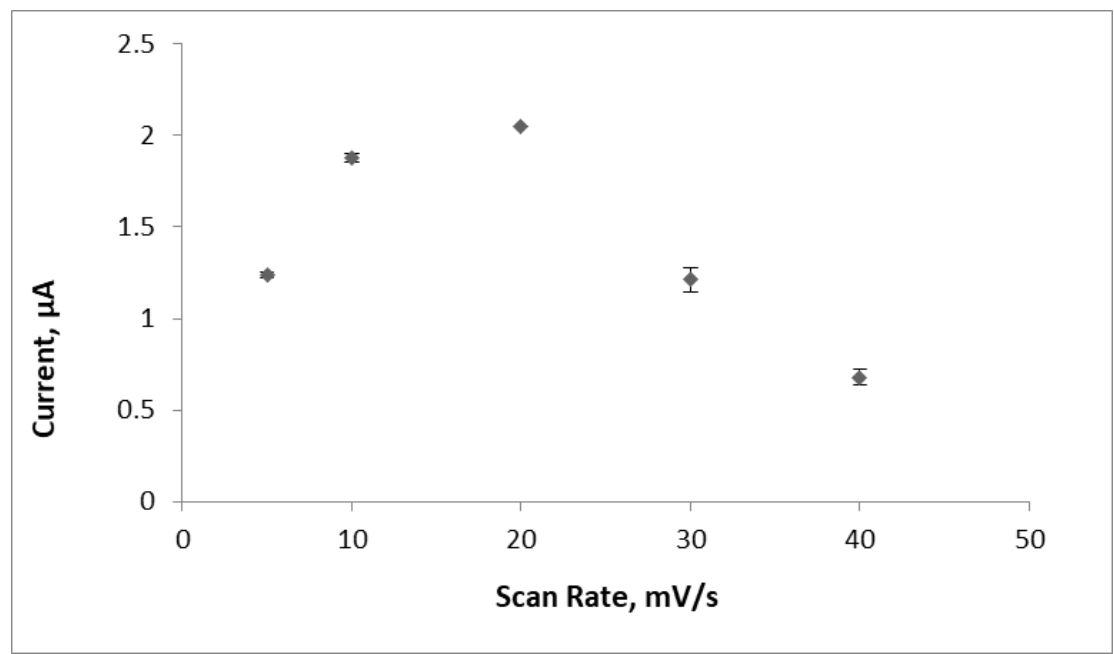

Figure 3. Effect of scan rate on epicatechin responses.

\section{Repeatability and Stability}

To test the repeatability of EC response and special stability of EC peaks on voltammograms obtained with the PI-based electrodes, fifteen scans were successively run using the same PI electrode in $0.1 \mathrm{M} \mathrm{PBS}(\mathrm{pH}$ $=7.00)$. Results are shown for both high concentration ( $4 \mathrm{mM})$ and low concentration $(0.02 \mathrm{mM})$ of epicatechin in Figure $4 \mathrm{~A}$ and $\mathrm{B}$, respectively. It can be deduced that repeatability of signal magnitude was quite high and stability with regard to EC peak shape and drift in voltammograms were extremely satisfactory. 

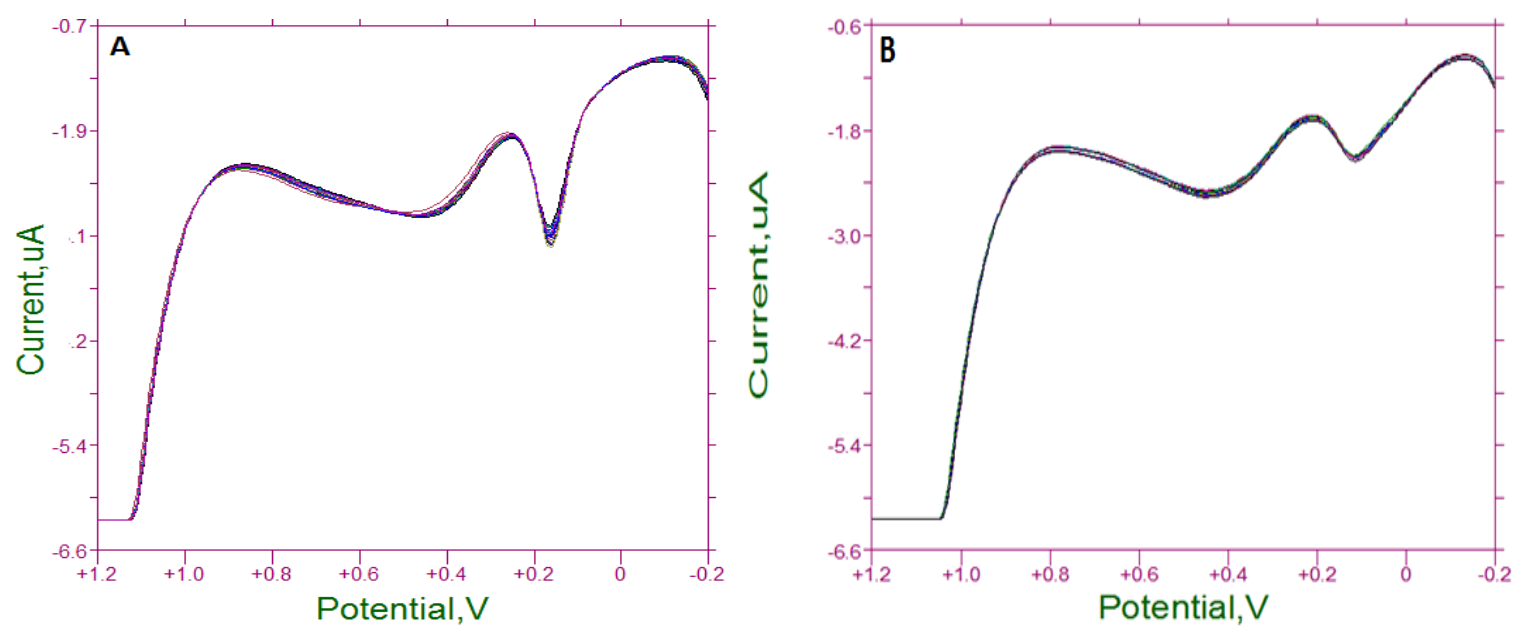

Figure 4. Stability on the same PI modified electrode in $0.1 \mathrm{M}$ PBS with $\mathrm{pH}=7$ at A: $4 \mathrm{mM}, \mathbf{B}: 0.02$ $\mathrm{mM}$ epicatechin concentration $(\mathrm{N}=15)$.

\section{Calibration curve for PI Electrodes}

Calibration studies were performed employing PI modified electrodes coated with optimum PI film thicknesses. DPV signals for increasing epicatechin concentration measured in $0.1 \mathrm{M}$ PBS $(\mathrm{pH}=7)$ are shown in Figure 5. As expected, epicatechin signal was shown to grow with increasing concentration.

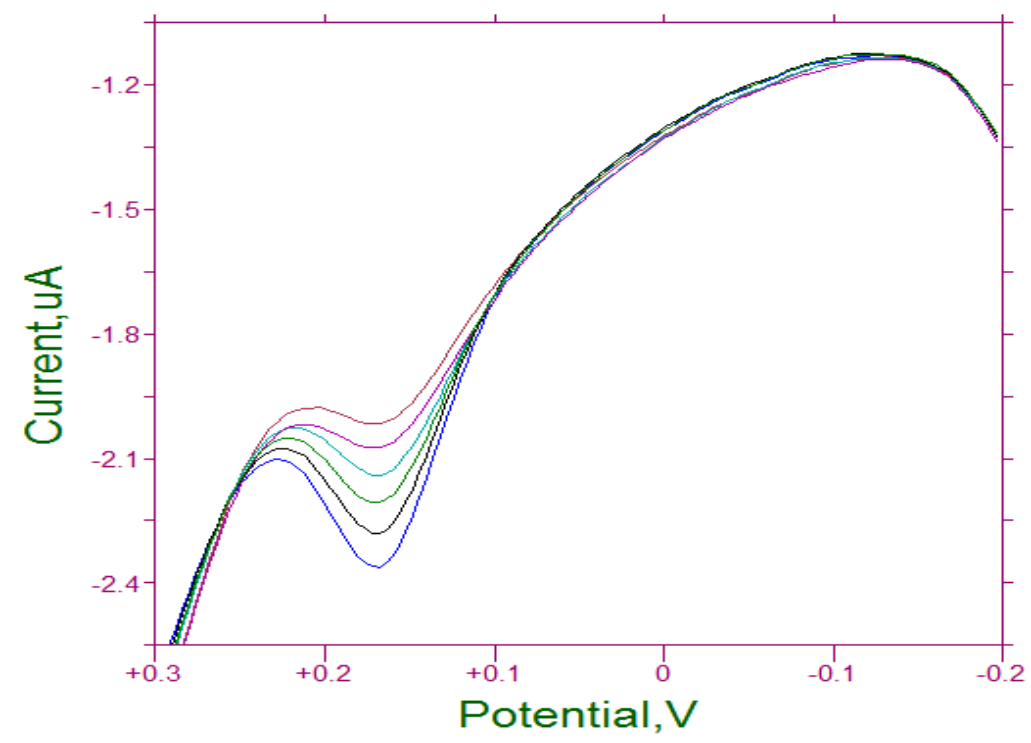

Figure 5: DPV of $0.05,0.10,0.15,0.20,0.25$ and $0.30 \mathrm{mM}$ epicatechin in $\mathrm{PBS} \mathrm{pH}=7.00$.

The measured peak currents are shown in Table 1 and the calibration graphs are shown in Figure 6 with $R^{2} 0.9969$.

Table 1. Calibration data.

\begin{tabular}{|l|c|c|c|c|c|c|}
\hline $\mathrm{C}, \mathrm{mM}$ & 0.05 & 0.10 & 0.15 & 0.20 & 0.25 & 0.30 \\
\hline $\mathrm{I}, \mu \mathrm{A}$ & $2.010 \pm 0.003$ & $2.066 \pm 0.026$ & $2.150 \pm 0.006$ & $2.221 \pm 0.007$ & $2.277 \pm 0.022$ & $2.362 \pm 0.021$ \\
\hline
\end{tabular}




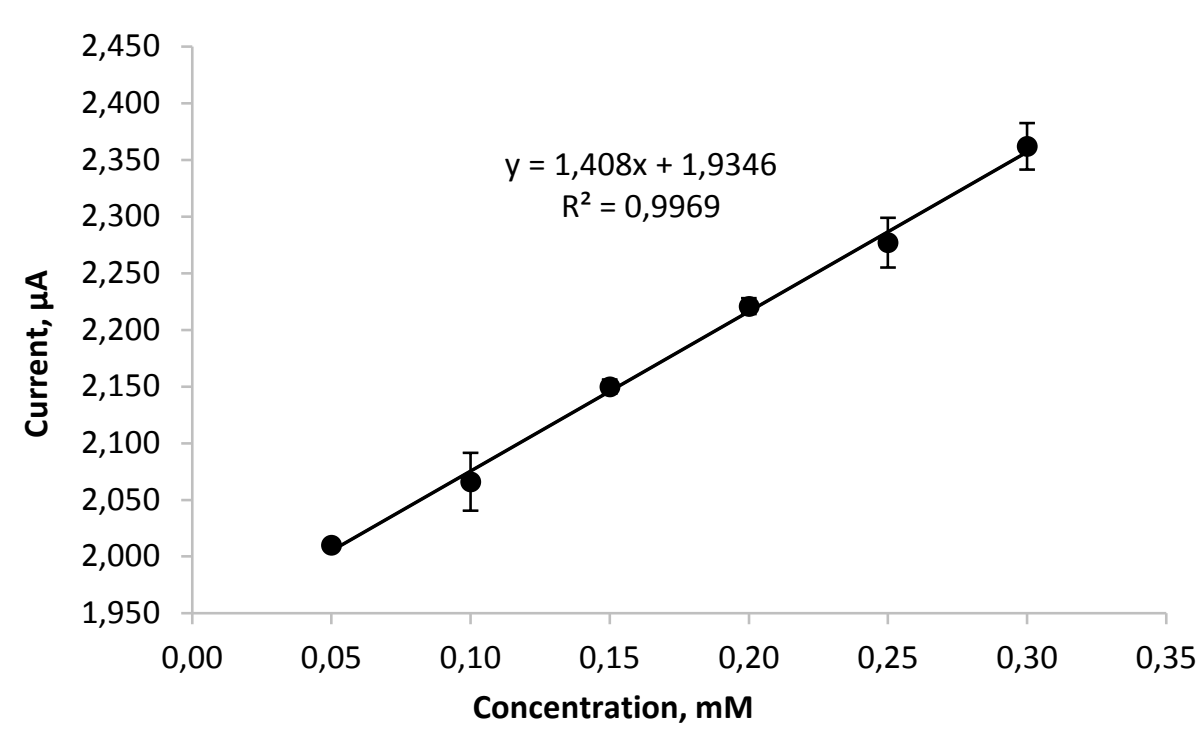

Figure 6. Calibration graph of epicatechin in PBS pH=7.00.

As the Fig 6 shows a linear response was obtained over a range of epicatechin concentrations from $0.05 \mathrm{mM}$ to $0.30 \mathrm{mM}$ in PBS with the indication that this electrode and method described in this work is a useful one for quantifying low levels of epicatechin in phosphate buffer solution, PBS, pH 7.00. Regression coefficient $\left(R^{2}\right)$ was found to be 0.9969. Limit of detection (LOD) was calculated as $1.8 \times 10^{-5} \mathrm{M}$.

The comparison of the properties of this sensor that was developed in this work with those mentioned in literature is shown in Table 2.

When Table 2 is examined, it can be stated that analytical parameters of the developed sensor, which involves no adsorption, deposition or incubation of the analyte on the electrode, is compatible with the data reported in literature.

\section{CONCLUSION}

A voltammetric electrode modified with polyimide membrane was prepared for the detection of epicatechin. In brief, our results demonstrate that poly(pyromellitic dianhydride-co-thionin) film can be easily coated on Pt electrode surfaces and that electrode with this polymeric film is extremely efficient in preventing the permeation of the mentioned electroactive or nonelectroactive interfering substances while allowing epicatechin passage through the film.

We believe that this polymeric film can be used as an inner / protective and a permselective membrane in epicatechin based sensor construction. This sensor has many important advantages such as rapid response time, low detection limit, low cost and high reproducibility for determination of epicatechin. 
Table 2. The comparison of the properties of sensor with the literature.

\begin{tabular}{|c|c|c|c|c|c|c|c|c|}
\hline Analyte & Electrode & Method & Polymer & $\begin{array}{c}\text { Linear } \\
\text { Range, } M\end{array}$ & $\mathbf{R}^{2}$ & LOD, M & pH & Reference \\
\hline Epicatechin & Pt & AdSV & PEDOT & $\begin{array}{c}6.9 \times 10^{-7} \text { to } \\
8.6 \times 10^{-6}\end{array}$ & 0.980 & - & 7 & (25) \\
\hline $\begin{array}{l}\text { Epigallocatechin } \\
\text { gallat }\end{array}$ & $\begin{array}{l}\text { MIP } \\
\text { modified } \\
\text { GC }\end{array}$ & DPV & $\begin{array}{l}\text { MIP/GO/ } \\
\text { GC }\end{array}$ & $\begin{array}{c}3 \times 10^{-8} \\
\text { to } \\
1 \times 10^{-5}\end{array}$ & 0.9989 & $8.78 \times 10^{-9}$ & 6 & (23) \\
\hline $\begin{array}{l}\text { Epicatechin } \\
\text { gallate } \\
\text { Epicatechin }\end{array}$ & GC & SWV & - & $\begin{array}{l}1 \times 10^{-8} \\
\text { to } \\
1 \times 10^{-5} \\
5 \times 10^{-7}\end{array}$ & $\begin{array}{l}0.9997 \\
0.9997\end{array}$ & $\begin{array}{l}3.26 \times 10^{-7} \\
4.27 \times 10^{-6}\end{array}$ & 2 & (26) \\
\hline Epicatechin & $C D$ & CE-ED & - & $\begin{array}{c}\text { to } \\
5 \times 10^{-5} \\
5 \times 10^{-5}\end{array}$ & 0.9960 & $4 \times 10^{-7}$ & 7.6 & (21) \\
\hline Epicatechin & Pt & DPV & PI & $\begin{array}{c}\text { to } \\
3 \times 10^{-4} \\
\end{array}$ & 0.9969 & $1.8 \times 10^{-5}$ & 7 & This work \\
\hline
\end{tabular}

(AdSV: Adsorptive stripping voltammetry, CE-ED: Capillary zone electrophoresis with electrochemical detection, CD: Carbon disc GC: Glassy carbon, MIP/GO/GC: Molecular imprinting polymer/graphene oxide/glassy carbon, PEDOT: poly(3,4-ethylenedioxythiophene),

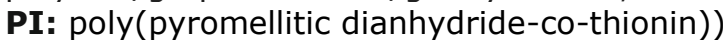

\section{REFERENCES}

1. Cui X, Fang X, Zhao H, Li Z, Ren H. An Electrochemical Sensor for Dopamine Based on Polydopamine Modified Reduced Graphene Oxide Anchored with Tin Dioxide and Gold Nanoparticles. Anal. Methods. 2017;9:53225332.

2. Jinn G.Y, Li H, Xu W.B. Sensitive Determination of Buformin Using PolyAminobenzoic Acid Modified Glassy Carbon Electrode. Journal of Pharmaceutical Analysis. 2012;26:458-461.

3. Gholivand M.B, Karimian N. Development of Piroxicam Sensor Based on Molecular Imprinted Polymer-Modified Carbon Paste Electrode. Materials Science and Engineering C. $2011 ; 31: 1844-1851$.

4. Wang J, Wang $\mathrm{H}$, Han S. Ultrasensitive Determination of Epicatechin, Rutin and Quercetin by Capillary Electrophoresis. Chemiluminescence Acta Chromatographica. 2012;24:679-688.

5. Sinha M, Das D.K, Manna K, Datta S, Ray T, Sil A.K, Dey S. Epicatechin ameliorates ionising radiation induced oxidative stress in mouse liver. Free Radical Research. 2012;467:842-849.

6. Das D.K, Sinha M, Khan A, Das K, Manna K, Dey S. Radiation Protection by Major Tea Polyphenol, Epicatechin. International Journal of Human Genetics. 2013;131:59-64.

7. Natsume M, Osakabe N, Oyama M, Sasaki M, Baba S, Nakamura Y. Structures of (-)
Epicatechin Glucuronide Identified From Plasma and Urine After Oral Ingestion of (-) Epicatechin: Differences Between Human and Rat. Free Radical Bio Med, 2003;34:840-849.

8. Abdulkhaleq L.A, Assi M.A, Noor M.H.M, Abdullah R, Saad M.Z, Taufiq-Yap Y.H. Therapeutic Uses of Epicatechin in Diabetes and Cancer. Veterinary World. 2017;106:2231-0916.

9. Berregi I, Santos J.I, Campo G, Miranda J.I. Quantitative Determination Of -) Epicatechin In Cider Apple Juices by ${ }^{1} \mathrm{H}$ NMR. Talanta. 2003; 61:139-145.

10. Philip M, Matthew J, Brian S, Catherine K.U, Dawn D. Method for the Determination of Catechin and Epicatechin Enantiomers in Cocoa-Based Ingredients and Products by High-Performance Liquid Chromatography: First Action 2013.04. 2014;972:506-509.

11. Song $R$, Cheng $Y$, Tian $Y$, Zhang Z.J. A Validated Solid-Phase Extraction HPLC Method for the Simultaneous Determination of Gallic Acid, Catechin and Epicatechin in Rhubarb Decoction. Chinese Journal of Natural Medicines. 2012;104:275-278.

12. Wang T.K, Yang Y.D, Du B, Yu S, Hou W.L. Simultaneous Determination of Gallic Acid, Protocatechuic Acid, Catechin, Epicatechin, Quercetin and Kaempferol in Chinese Chestnut Castanea mollissima Blume) Kernel by HighPerformance Liquid Chromatography with Diode Array Detection. Acta Chromatographica. 2014;263:539-550.

13. Ricardo FN, Tamara A, Sandra MMS, Pérola O.M, Tais G, Marcílio SSC, Guilherme MG. 
Versatile Chromatographic Method for Catechin Determination in Development of Topical Formulations Containing Natural Extracts. Biomedical Chromatography. 2018;32:4062-4069.

14. Fecka I, Cisowski W, Luczkiewicz M. Determination of Catechin and Epicatechin in An Extract From Uncaria Tomentosa Bark by TLC with Chemically Modified Stationary Phases. JPC-Journal of Planar Chromatography-Modern TLC. 2001;146:405408.

15. Glavnik V, Simonovska B, Vovk I. Densitometric Determination of $(+)$-Catechin and (-)-Epicatechin by 4Dimethylaminocinnamaldehyde Reagent. J Chromatogr A. 2009;121620:4485-4491.

16. Jaiswal $Y$, Tatke $P$, Gabhe $S$, Vaidya $A$. Rapid High Performance Thin Layer Chromatographic Method for Quantitation of Catechin from Extracts of Cashew Leaves - a Short Report. Pol. J. Food Nutr. Sci. 2013; 631:49-54.

17. Reich E, Schibli A, Widmer V, Jorns R, Wolfram E, DeBatt A.HPTLC Methods for Identification of Green Tea and Green Tea Extract. Journal of Liquid Chromatography \& Related Technologies. 2006;29:2141-2151.

18. Solich P, Opletal L, Sovova M. Comparison of Different Methods for the Spectrophotometric Determination of -)Epicatechin. Pharmazıe. 1996;5112:954-956.

19. Singh HP, Ravindranath SD, Singh C. Analysis of Tea Shoot Catechins: Spectrophotometric Quantitation and Selective Visualization on Two-Dimensional Paper Chromatograms Using Diazotized Sulfanilamide. J. Agric. Food Chem.,1999;473: 1041-1045.

20. Luthria, $D L$, Jones $A D$, Donovan $J L$, Waterhouse AL. GC-MS Determination of Catechin and Epicatechin Levels in Human Plasma.HRC Journal of High Resolution Chromatography. 1997;2011:621-623.
21. Cao $Y H$, Zhang $X$, Ding $X H$, Fang $Y Z$, Ye JN. Determination of Caffein, Epicatechin and Ascorbic Acid in Tea Samples by Capillary Zone Electrophoresis with Electrochemical Detection. Chinese Journal of Analytical Chemistry. 2001;299:1072-1075.

22. Wang XG, Li J, Fan YJ. Fast Detection of Catechin in Tea Beverage Using A PolyAspartic Acid Film Based Sensor. Microchim. Acta. 2010;169:173-179.

23. Liu Y, Zhu L, Hu Y, Peng X, Du J. A Novel Electrochemical Sensor Based on A Molecularly Imprinted Polymer for The Determination of Epigallocatechin Gallate. Food Chem. 2017;221:1128-1134.

24. Chatterjee TN, Das D, Roy RB, Tudu B, Sabhapondit $S$, Tamuly $P$, Pramanik $P$, Bandyopadhyay R. Molecular Imprinted Polymer Based Electrode for Sensing Catechin $+C)$ in Green Tea. IEEE Sensors Journal. 2018;186:2236-2244.

25. Pigani L., Seeber R, Bedini A, Dalcanale E, Suman M. Adsorptive-Stripping Voltammetry at PEDOT-Modified Electrodes. Determination of Epicatechin. Food Anal. Methods. $2014 ; 7: 754-760$.

26. Novak I, Šeruga M, Komorsky-Lovrić Š. Square-wave and cyclic voltammetry of epicatechin gallate on glassy carbon electrode. Journal of Electroanalytical Chemistry. 2009;631:71-75.

27. Köytepe S., Paşahan A., Ekinci E., Seçkin T. Synthesis, characterization and H2O2sensing properties of pyrimidine-based hyperbranched polyimides European polymer journal 2005;411: 121-127.

28. Paşahan A., Köytepe S., Ekinci E. Synthesis, characterization of naphthalenebased polyimides, and their use as immobilized enzyme membrane. Polymers for Advanced Technologies 2011;2212: 19401947.

29. Sheng W, Chen Q, Yang P, Chen C. Synthesis, Characterization, and Enhanced Properties of Novel Graphite-Like Carbon Nitride/Polyimide Composite Films. High Performance Polymers. 2015;27:950-960. 